\title{
Forest Certification in Canada and Around the World
}

I read with interest the item on page 146 in the March/April issue of The Forestry Chronicle under the heading "Of Relevance" Perspective on FSC-Certified Lumber. I think CIF/IFC members might be interested in a more comprehensive up-date on the status of certification in Canada and around the world. Tony Rotherham R.P.F.]

orest certification has become a common practice for many forest product companies and forest management organizations around the world. There are approximately 310 million ha of forest certified to a variety of standards worldwide. This represents approximately $10 \%$ of the world's forests. Canada has $40 \%$ of all certified forestland in the world, more than any other country.

Let us look first at Canada, the global leader. There are three certification programs used by Canadian forest management organizations:

- CAN CSA Z809 - the SFM standard developed by a multi-interest Technical Committee working under the aegis of the Canadian Standards Association (CSA). This standard is based on the Criteria and Indicators for Sustained Forest Management (SFM) approved by the Canadian Council of Forest Ministers (CCFM). The Prefix "CAN" indicates that it is a National Standard of Canada approved by Canada's national standards governing body-The Standards Council of Canada.

- The Forest Stewardship Council (FSC) has three regional standards approved for use in Canada. They are FSC Boreal, FSC British Columbia, and FSC Maritimes. FSC International has not approved the FSC Great Lakes - St. Lawrence standard but several areas of forest have been certified to the requirements of this draft standard.

- The Sustainable Forestry Initiative (SFI) 2005-2009 standard is also extensively used in Canada. SFI Inc. is a 501c(3) non-profit organization and is overseen by a three-chamber Board of Directors representing social, environmental and economic sectors.
The Canadian Sustainable Forestry Certification Coalition, in its January $31^{\text {st }}, 2008$ "Certification Status Report" (www.CertificationCanada.org) reports the three programs had registered certifications totalling 137.8 million ha of forest with an Allowable Annual Cut (AAC) of 122 million $\mathrm{m}^{3}$. This report is the only certification status report that includes a statement of production from the certified forests. Volume of production from certified forests indicating the supply of certified wood is a more meaningful statistic than the area certified. The areas and Allowable Annual Cut for these certification programs are shown in Table 1. ment. The PEFC national working groups base their standards on the Criteria and Indicators for SFM approved by their national governments through the UN Intergovernmental Process on C\&I for SFM. Both programs review the standards developed by national working groups before approving them. The FSC does this internally. The PEFC engages an independent forest consulting firm to review and report on the proposed standard to ensure that it meets the PEFC requirements for content and the development process. An independent Panel of Experts and the PEFC Board review the consultant's report and, if satisfactory, the new stan-

Table 1 - Canadian Certified Forest Programs

\begin{tabular}{lcccc}
\hline Program & AAC Millions $\mathbf{~}^{\mathbf{3}}$ & $\mathbf{\%}$ & Area Millions ha & $\%$ \\
\hline CSA & 62.7 & 56 & 77.8 & 56 \\
SFI & 40.9 & 37 & 39.1 & 28 \\
FSC & 8.9 & 8 & 24.4 & 18 \\
Total $^{*}$ & $\mathbf{1 2 2}$ & $\mathbf{1 0 0}$ & $\mathbf{1 3 7 . 8}$ & $\mathbf{1 0 0}$
\end{tabular}

*Some forests have been certified to two standards; the total may be less than the sum of all three programs to avoid double counting

Canadian forest management organizations have achieved certified status on 138 million ha $(74 \%)$ of the estimated 185 million ha of forest land under management in this country. One hundred and sixty million ha was under public ownership and 25 million ha under private ownership.

\section{International Forest Certification}

Looking now at the international scene, there are two forest certification programs that operate around the world. These are the FSC and the Programme for the Endorsement of Forest Certification schemes-better known by its acronym, PEFC. The CSA and SFI standards used in Canada are fully endorsed and recognized members of the PEFC program.

The international programs have a lot in common and one significant difference. Both FSC and PEFC work with national working groups that develop forest management standards. The FSC groups base their standards on the 10 FSC Principles of good forest manage- dard is approved by the PEFC Members as a PEFC-endorsed Standard.

The significant point of difference between the FSC and PEFC is that the PEFC will only recognize certifications to standards that have been fully reviewed and endorsed by the PEFC Board of Directors and PEFC members. But the FSC recognizes certifications in countries where there are no FSCapproved standards.

The PEFC has endorsed standards in 24 countries. Currently, 203.7 million ha have been certified in 19 of these countries. Map A shows the 24 countries with PEFC-approved standards. Nineteen of these countries have registered certifications totalling 203.7 million ha with the PEFC office in Geneva.

The FSC has approved standards in only 14 of the 79 countries where FSC certifications have been carried out (FSC Accredited Forest Stewardship Standards-20 March 2008). FSC International in Bonn recognizes all 103.5 million ha of FSC-certified forest despite the fact that there are no 


\begin{tabular}{|c|c|c|c|c|c|c|}
\hline Program & $\begin{array}{l}\text { Countries } \\
\text { with } \\
\text { approved } \\
\text { standards }\end{array}$ & $\begin{array}{c}\text { Forest } \\
\text { certified } \\
\text { in these } \\
\text { countries } \\
\text { (millions ha) }\end{array}$ & $\begin{array}{c}\% \text { of } \\
\text { program }\end{array}$ & $\begin{array}{l}\text { Countries } \\
\text { with no } \\
\text { approved } \\
\text { standards }\end{array}$ & $\begin{array}{c}\text { Forest } \\
\text { certified } \\
\text { in these } \\
\text { countries } \\
\text { (millions ha) }\end{array}$ & $\begin{array}{c}\% \text { of } \\
\text { program }\end{array}$ \\
\hline PEFC & $\begin{array}{l}24 \text { (19 with } \\
\text { certified forests) }\end{array}$ & 203.7 & 100 & $\mathrm{X}$ & $\mathrm{X}$ & $\mathrm{X}$ \\
\hline FSC & 14 & 57.7 & 56 & 65 & 45.8 & 44 \\
\hline
\end{tabular}

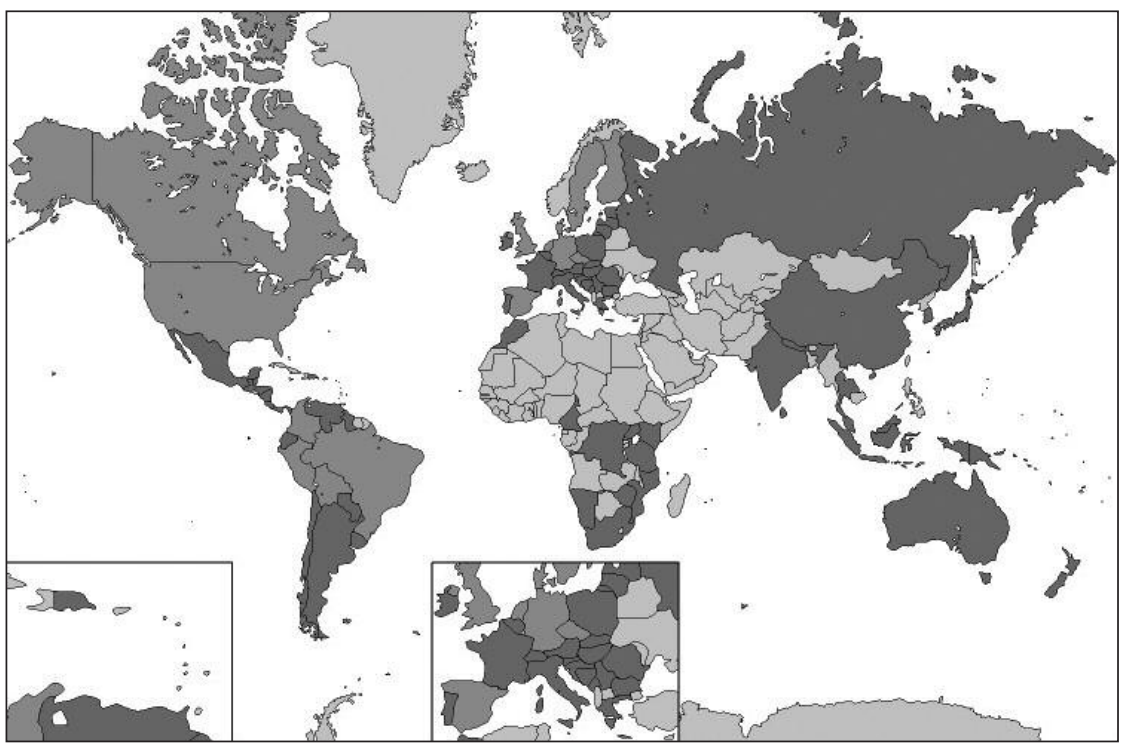

Map A. 24 Countries with PEFC Standards; 19 with certified forests.

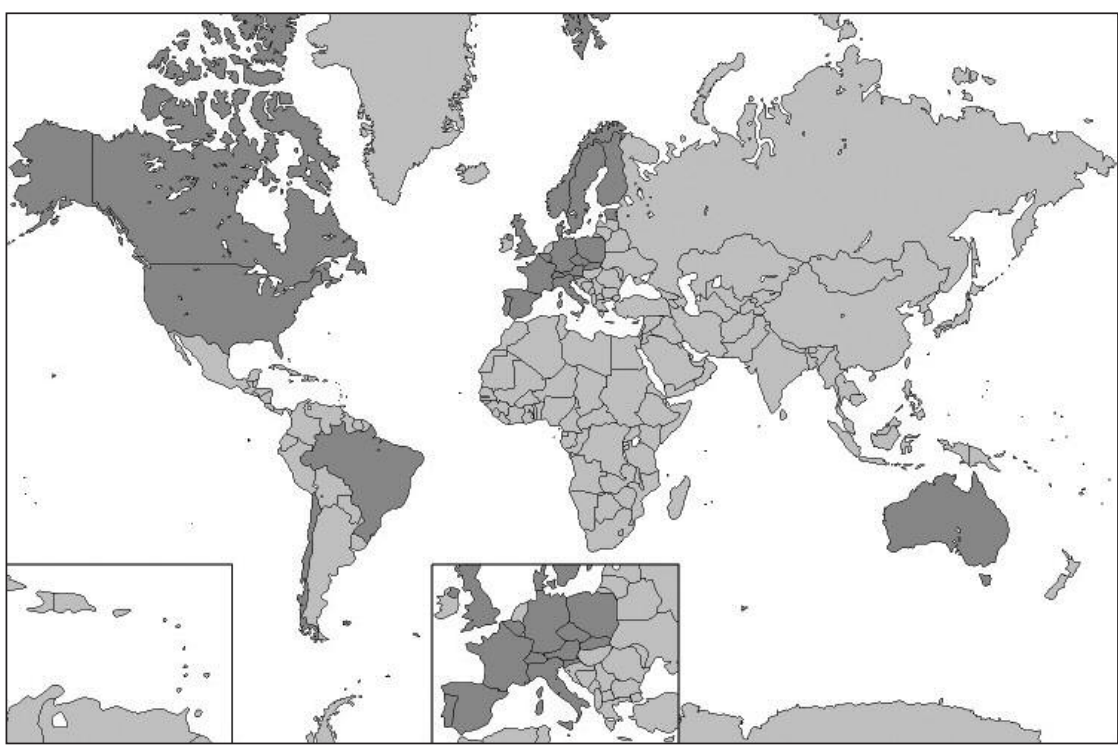

Map B. A total of 79 Countries with FSC certifications; 14 countries with approved standards; 65 countries without approved standards. approved FSC standards in 65 of the countries in which FSC lists certifications. The 14 countries with approved standards have 57.7 million ha certified (56\%). The 65 countries without FSCapproved standards have 45.8 million ha of certified forest (44\%). Map B shows all 79 countries where the FSC has registered standards and certifications. Countries with FSC standards are shown in medium grey. Countries with FSC certifications, but no recognized FSC standards are shown in dark grey.

Certification to standards that have not received final approval is a significant departure from established international standards procedure. A table summarizing these differences is shown above.

It is interesting to note that ad hoc working groups have developed most of the forest management standards used around the world. There are several notable exceptions. Technical committees working through their national standards institutes developed the CSA SFM standard, and the PEFC forest management standards in Australia, Chile and Brazil. Working through national standards institutes provides an added measure of rigour to the development process and assists with resolution of dissenting opinion. Ad hoc groups have generally done a good job.

There are other certification programs in operation. The Malaysian Timber Council (MTCC) has a certification program for Malaysian forests. Several certifications have been issued.

All programs have the same objectives-improve forest management, try to ensure that wood from illegal logging does not enter the supply chain, provide assurance to customers that wood bearing the PEFC, SFI, CSA, MTCC or FSC logos comes from well-managed forests. 